\title{
Contraconsciência, luta social e transformação
}

\section{Giorgia Prates}

Enfrentamos uma nova onda de retrocesso e complexidade da dinâmica de globalização capitalista. Interesses capitalistas, Estado e mídia formam uma aliança que gera desigualdade tanto dentro do país quanto internacionalmente. Uma das maiores injustiças sociais do Brasil é o monopólio midiático que sustenta um estado esquizofrênico com consciências anuladas. As pessoas aceitam uma realidade manipulada que fortalece o Estado de exceção. A luta social existe para tentar corrigir o que impede o ser humano de buscar sua liberdade e transformar o mundo em que se insere. Ela permite rebuscar o sentido de pertencimento nas ações cotidianas e resistir nesses espaços, criando uma contraconsciência que é um meio de sobrevivência. Os males do passado podem e devem ser modificados no presente para evitar males no futuro.

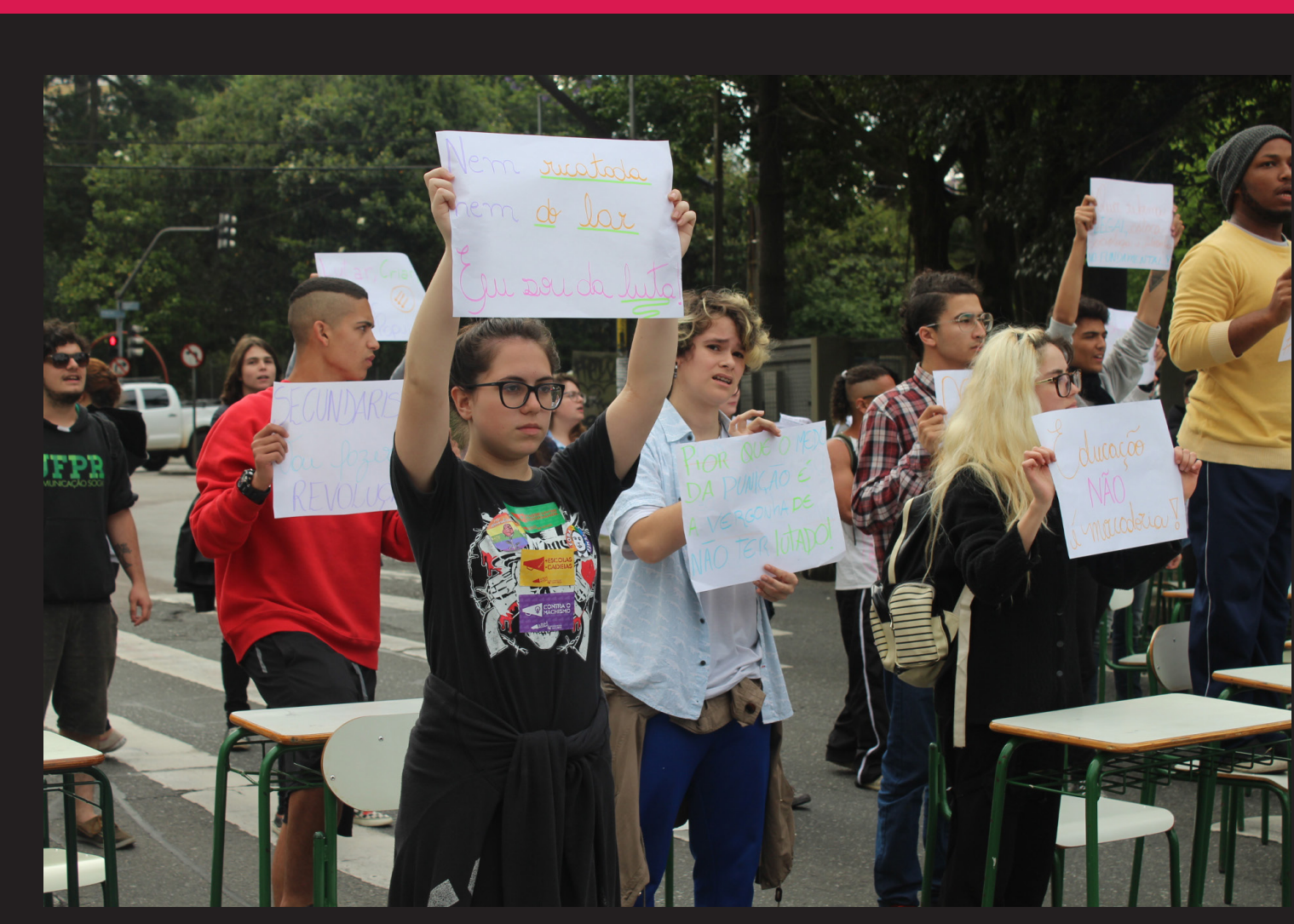

1. Estudantes secundaristas foram às ruas Curitiba para reivindicar uma educação pública de qualidade e a revogação da PEC 241 e MP do ensino médio
1 Formada em Fotografia pela Universidade Tuiuti do Paraná, graduanda de Pedagogia pela UFPR, militante do Levante Popular da Juventude e comunicadora popular. 


\section{FOTOGRAFIAS}

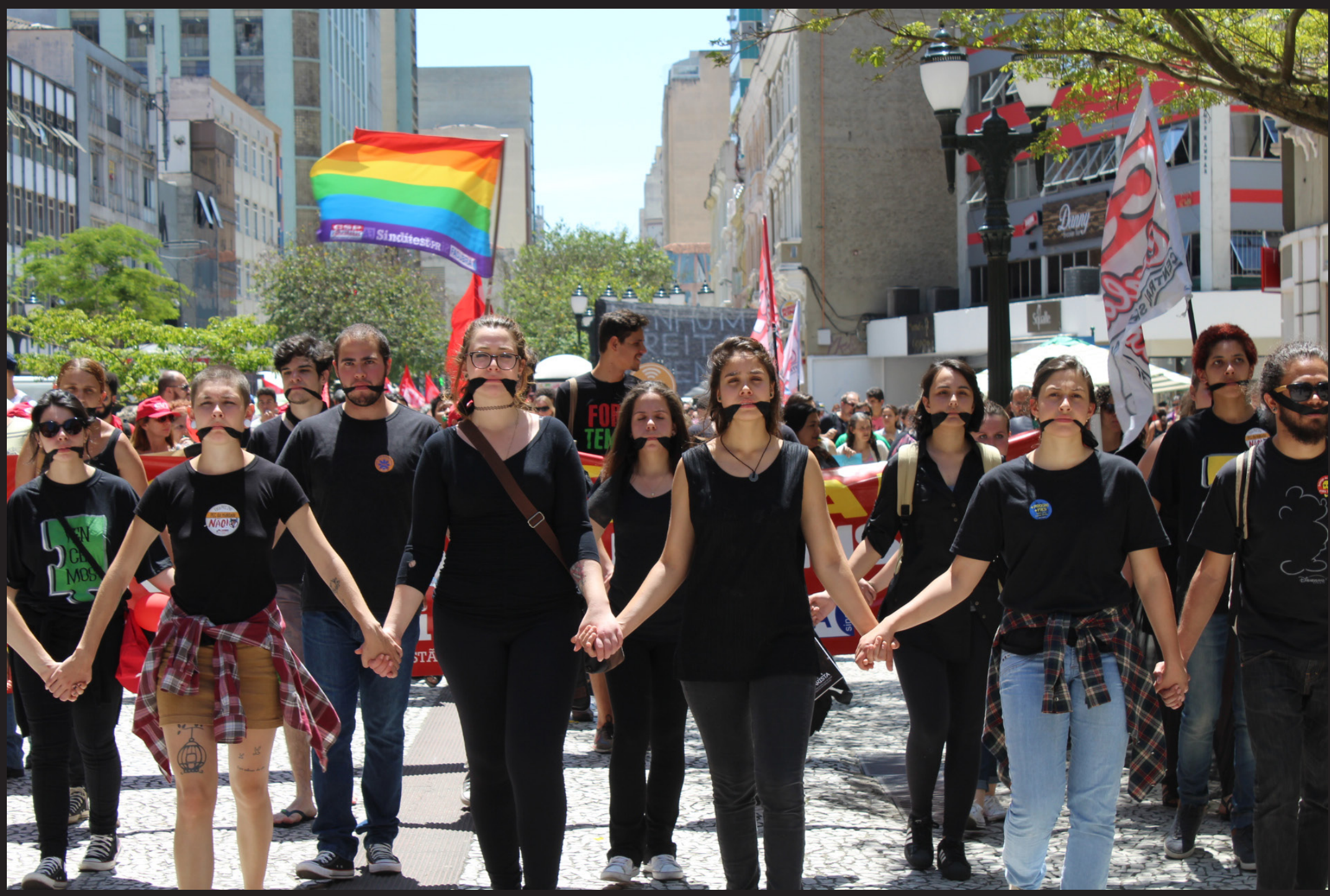

2. Lei da mordaça: Artistas/alu-

nos do Departamento e Ocupa

DeArtes da UFPR manifestam

Contra a PEC 241 e MP do

ensino médio. 


\section{FOTOGRAFIAS}

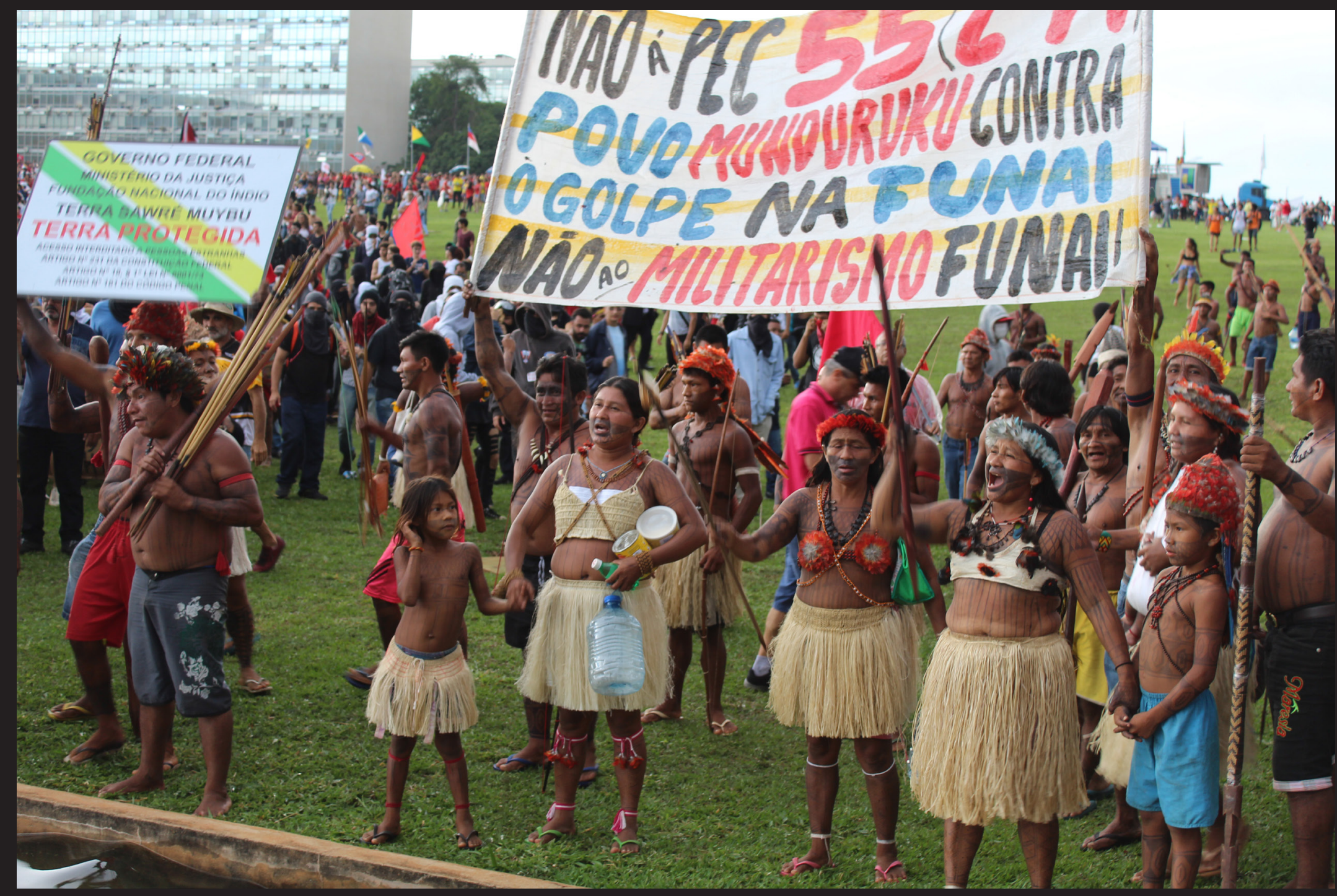

3. Indígenas de vários lugares

do país se reúnem em Brasilia

para exigir a demarcação de

suas terras e a desmilitariza-

ção da Funai. 


\section{FOTOGRAFIAS}

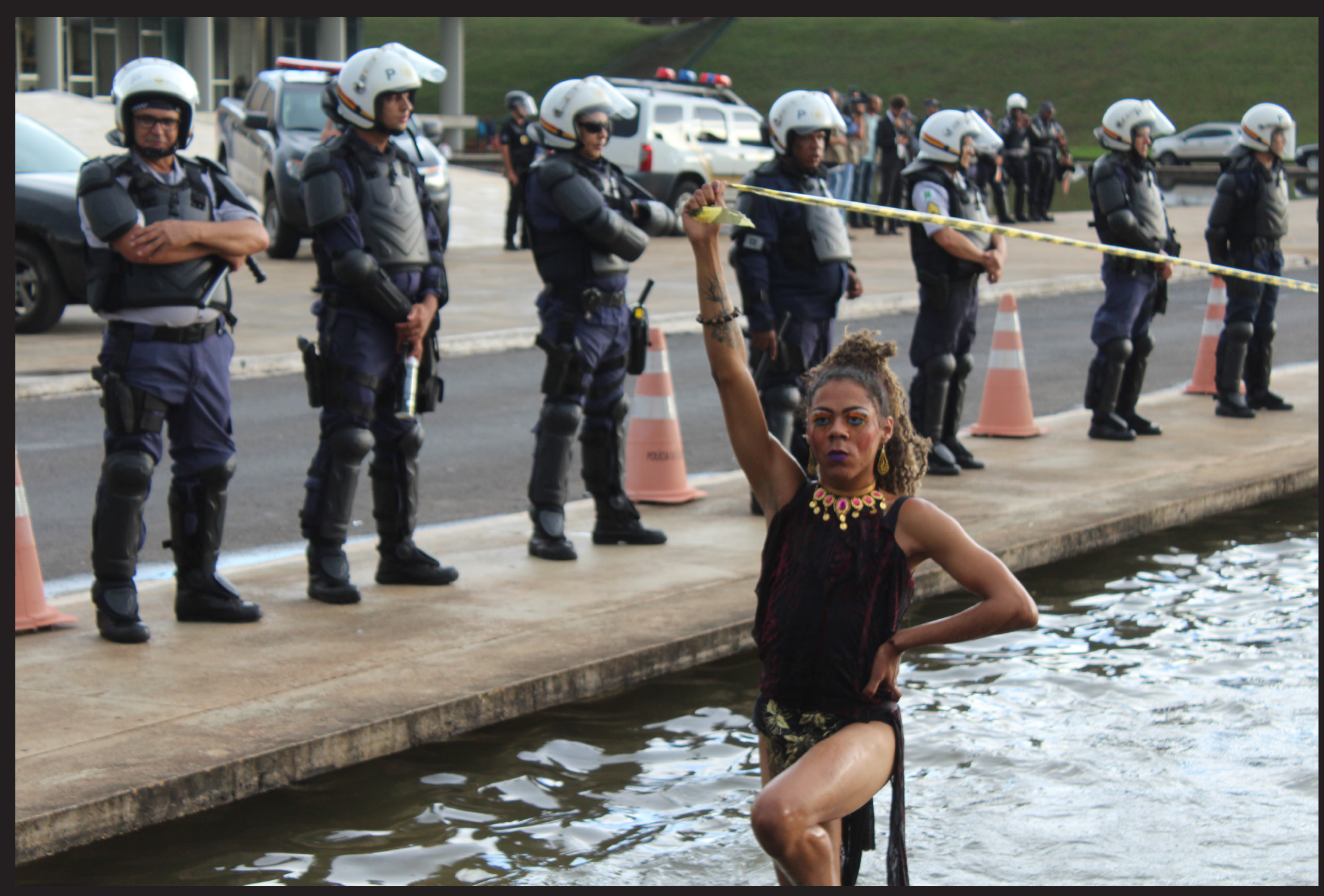

4. Trans faz performance em frente à Câmara em repúdio à

violência contra a população LGBTTS. 


\section{FOTOGRAFIAS}

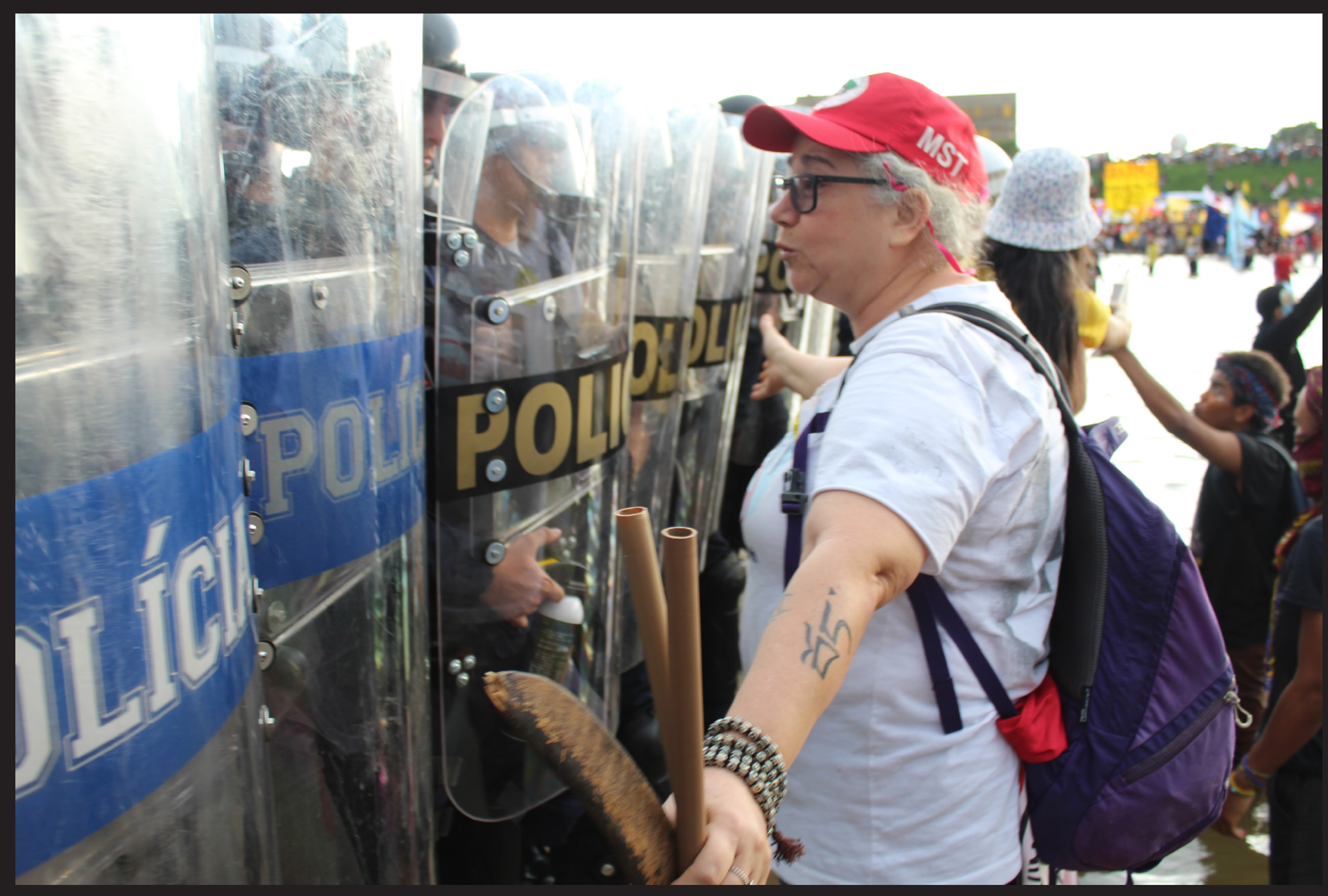

5. Resistência: Mulheres na linha de frente contra a violência. 


\section{FOTOGRAFIAS}

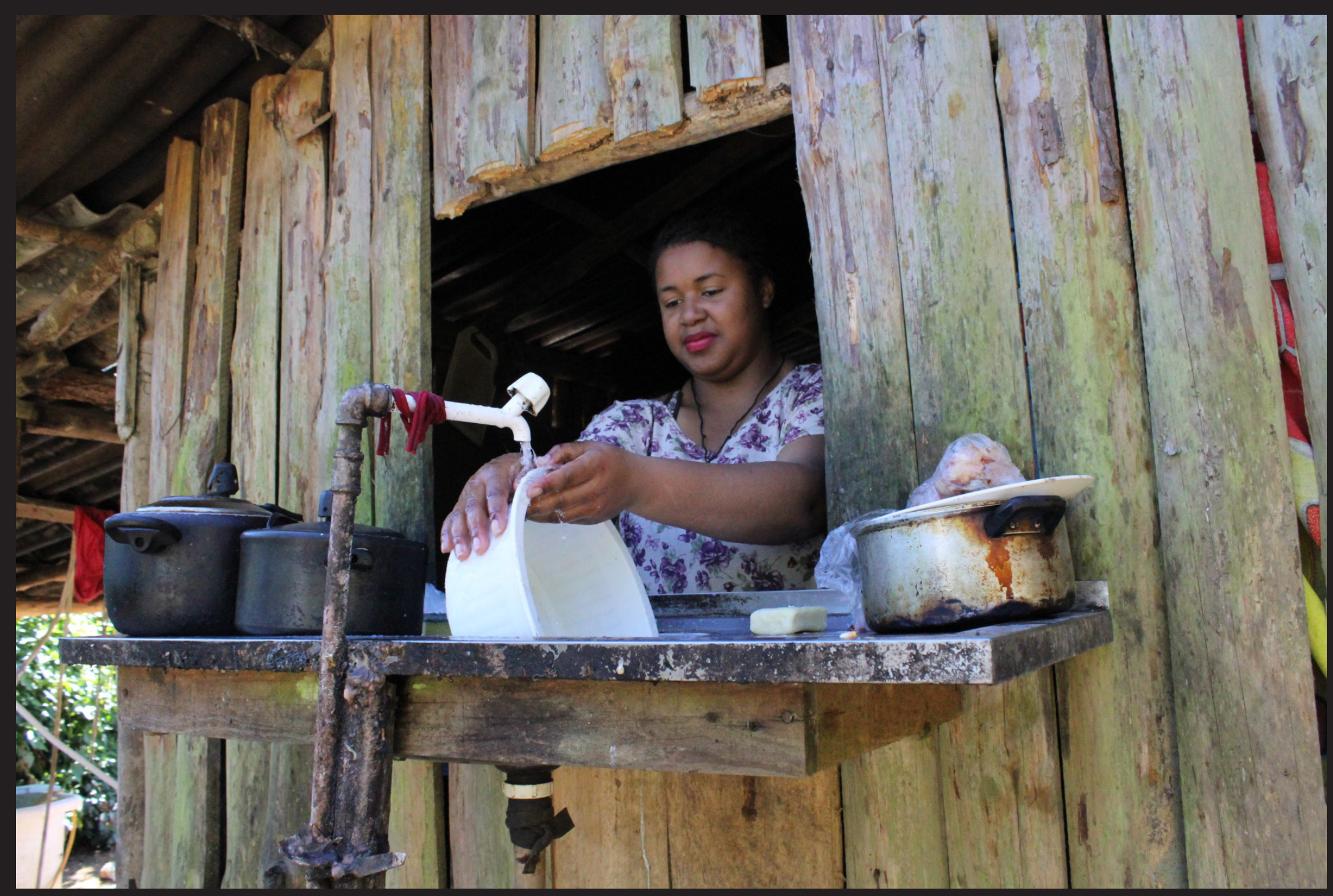

